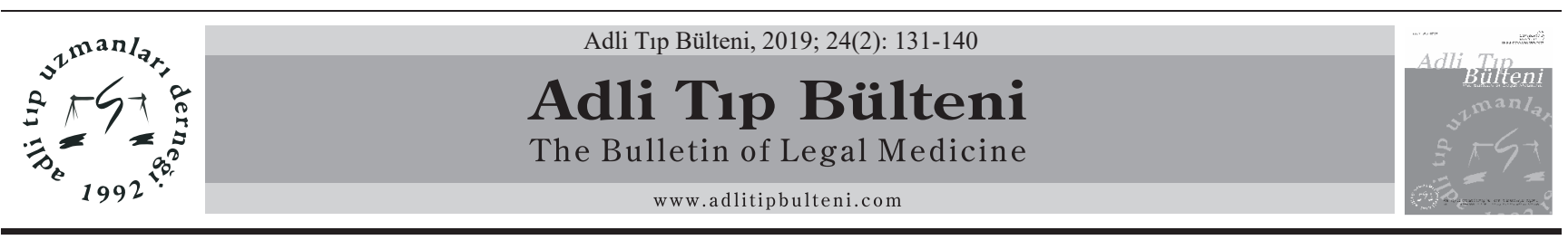

DERLEME / REVIEW

\title{
Biyocoğrafik Soy Tahmini ve Adli Bilimlerde Kullanımı
}

\author{
Inferring Biogeographic Ancestry and Its Use in Forensic Sciences \\ Özlem Bülbül*, Gönül Filoğlu
}

\begin{abstract}
Öz
Adli bilimlerde SNP (Single nucleotide polymorphism, tek nükleotid polimorfizm) markırları kimliklendirmede, fenotip belirlemede, nesep ve soy tayininde kullanılmaktadır. Biyocoğrafik soy tahmininde farklı coğrafik bölgelerde bulunan popülasyonlar arasındaki farklılıkları gösteren soy SNP markırları (AISNPs, Ancestry Informative SNP Markers) kullanılmaktadır. AISNP markırları ile bir kişinin biyocoğrafik orijini ve her biyocoğrafik bölgeden alınan genetik soy yüzdesi tespit edilebilir. Bu bilgiler adli bilimlerde bilinmeyen bir şüphelinin, felaket kurbanlarının veya kayıp kişilerin kimliklendirilmesinde kullanılabilir. Bu makalede biyocoğrafik soy kavramı, biyocoğrafik soy tahmininde kullanılan AISNPs panelleri, uygulama yöntemleri, kullanılan istatistiksel yöntemler ve güncel adli uygulamalar tartış1mıştır.
\end{abstract}

Anahtar Kelimeler: Biyocoğrafik Soy; SNP; Adli Genetik.

\section{Abstract}

In forensic applications SNP (Single nucleotide polymorphism) markers are used for identification, determination of phenotypes, lineage and ancestry. Ancestry informative SNP markers (AISNPs), which show differences between populations in different geographic regions, are used for estimating of the biogeographic ancestry. The biogeographical origin of a person and the percentage of genetic lineage taken from each biogeographic region can be determined using AISNP markers. This information may assist forensic investigations of unknown contributors or identification of missing persons and disaster victims. In this review, biogeographic ancestry concept, AISNPs panels used in estimation of the biogeographic ancestry, application methods, statistical methods, and current forensic applications has been discussed.

Keywords: Biogeographic Ancestry; SNP; Foresic Genetics.

\section{DOI: 10.17986/blm.2019250174}

Özlem Bülbül: PhD., İstanbul Üniversitesi-Cerrahpaşa, Adli Tıp Enstitüsü, İstanbul Eposta: ozlem.bulbul@istanbul.edu.tr ORCID iD: https://orcid.org/ 00000003-2920-7614

Gönül Filoğlu: PhD., İstanbul Üniversitesi-Cerrahpaşa, Adli Tıp Enstitüsü, İstanbul

Eposta: gfoglu@istanbul.edu.tr ORCID iD: https://orcid.org/ 00000002-8807-317X

Bildirimler/ Acknowledgement: Yazarlar bu makale ile ilgili herhangi bir çıkar çatışması bildirmemişlerdir. Yazarlar bu makale ile ilgili herhangi bir finansal destek bildirmemişlerdir.

The authors declare that they have no conflict of interests regarding content of this article.

The Authors report no financial support regarding content of this article.

Geliş: 23.11.2018

Düzeltme: 28.01 .2019

Kabul: 31.01 .2019

p-ISSN: $1300-865 \mathrm{X}$

e-ISSN: $2149-4533$ 


\section{Giriş}

Adli bilimlerde biyolojik delillerin değerlendirilmesinde rutin analizlerde en fazla kullanılan STR (Short Tandem Repeat, Kısa Tekrar) markırları olmasına rağmen bu markırlara alternatif veya tamamlayıcı olarak kullanılabilecek markırlar da bulunmaktadır. 2000'li yıllardan itibaren insan genomunun tamamının dizinlenmesiyle beraber genetik yapı hakkında bilgi veren daha fazla markır keşfedilmiştir. Bu markırlardan biri SNP (Single nucleotide polymorphism, tek nükleotid polimorfizm) markırları olup adli bilimlerde yaygım olarak kullanılacağı öngörülmektedir. SNP markırları tek bir nükleotidde oluşan DNA sekans varyasyonları olup bütün genomda oldukça sık görülür. Genom boyunca dağılmış olan bu markırlar genetik yapı hakkında pek çok bilgiyi içerir. SNP markırları adli uygulamalarda kimliklendirmede, fenotip belirlemede, nesep ve soy tayininde kullanılmaktadır (1-4). $\mathrm{Bu}$ yazıda biyocoğrafik soy tahmininde kullanılan SNP markırları (AISNPs- Ancestry Informative SNPs) ve bu markırların adli bilimlerde kullanımının güncel gelişmeleri tartışılacaktır.

\section{Biyocoğrafik Soy Kavramı ve Soy SNP Markırları (AISNPs- Ancestry Informative SNPs):}

Amerika Ulusal İnsan Genomu Araştırma Enstitüsü Irk, Etnik köken ve Genetik Çalışma Grubu (the Race, Ethnicity, and Genetics Working Group of the National Human Genome Research Institute) popülasyonların tabakalaşmasını incelerken ırksal, atasal ya da etnik etiketler yerine biyocoğrafik soy teriminin kullanılmasını önermiştir (5). Bireylerin biyocoğrafik soy tahminleri; evrim çalışmalarında geçmişin yeniden canlandırılmasında, popülasyon karışımlarının incelenmesinde, popülasyonların demografik geçmişlerinin açıklanmasında, fiziksel özellikler ile ilgili ilişkilerin saptanmasında, genetik haritalamada, hastalık fenotiplerinin toplumlardaki riskleri ve dağılımları hakkında bilgi verirler $(6,7)$. Farklı coğrafik bölgelerde bulunan popülasyonlar arasındaki farklılıklar1 gösteren markırlara soy (AIMs- Ancestry Informative Markers) markırları denir. AIMs ile bir kişinin atalarına ait biyocoğrafik orijini ve her biyocoğrafik bölgeden alınan genetik soy yüzdesi tespit edilebilir. Biyocoğrafik soya ait bu bilgiler adli bilimlerde suçluya ulaşmak için kullanılabilir. Popülasyonlar arası farklara dayanarak suçlunun hangi topluma ait olabileceğinin tespit edilebileceği gibi fiziksel özellikler ile ilgili veriler kullanılarak (göz, saç, ten renkleri gibi) da kimliklendirme yapılabilir. Bu tarz bir kimliklendirmeye "Moleküler görgü tanıklığı" da denilmektedir $(8,9)$.
STR lokusları adli bilimlerde rutin analizlerde kullanıldığı gibi nadir de olsa biyocoğrafik soy tahmininde kullanılmaktadır $(10,11)$. Ancak adli genetikte kullanılan STR markırları kimliklendirme için çok iyi markırlar olmalarına rağmen popülasyonlar arası alel paylaşımları yüksek olduğundan biyocoğrafik soy belirlemede yeterli bilgi vermemektedirler. Son y1llarda Stanford Üniversitesinde Rosenberg ve ekibi tarafından yapılan bir çalışmada rutin analizlerde kullanılan ve kimliklendirme için seçilmiş 13 CODIS ile birlikte 779 STR lokusu kullanılarak bu lokusların biyocoğrafik soy hakkında bilgi verip vermedikleri araştırılmıştır (12). Söz konusu çalışmada CODIS 13 STR lokusunun az da olsa biyocoğrafik soy ile ilgili bilgi verdiği belirlenmiştir (12). Ancak sadece STR lokuslarıyla elde edilen soy bilgisi biyocoğrafik soyun tahmini için yeterli olmamaktadır. Diğer bir çalışmada araştırıcılar güvenilir sonuç elde etmek için AIMs STR ile beraber AISNPs markırlarının da çalışılmasını önermiştir (11).

AISNPs markırları popülasyonlar arasında görülen varyansların bilinmesi ile kökenleri anlamada, popülasyonların göç yollarını belirlemede ve genetik çalışmalarda alel sıklıklarının belirlenmesinde kullanılırlar. AISNPs markırları biyocoğrafik soyun belirlenmesinde en sık kullanılan polimorfizm çeşidi olup diğer markırlara göre çok daha geniş bir veri bankasına sahiptir. Bu markırların en büyük avantajlarından biri bireylerin ataları ile ilgili tek taraflı bir bilgi (mtDNA ve Y kromozomu bilgileri) yerine her iki atadan gelen karışık coğrafi kalıtıma ait tüm bilginin elde edilebilmektedir (13-15).

AISNPs adli bilimlerde olay yerinden ele edilen ve kime ait olduğu bilinmeyen biyolojik örneklerin/delilin DNA profilinin hangi topluma ait olduğu tespit edilerek şüpheli/kişi hakkında bilgi edinilmeye çalışılır. Özellikle delilden STR profili elde edilemediği, elde edilen DNA profili veri tabanında bulunmadığı veya görgü tanıklarının verdiği bilgilerin güvenilir olmadığı adli olgularda şüpheliyi tanımlayabilecek biyocoğrafik soy bilgisi çok önemlidir (8, 15-17). Adli bilimlerde 2000'li yılların başından beri yapılan SNP çalışmaları ile birçok SNP paneli geliştirilmiştir (17-21). Adli bilimlerde ilk olarak geliştirilen AISNPs panellerinden biri Phillips ve arkadaşları tarafindan oluşturulan 34-plex panelidir (18). Bu panel kriminal laboratuvarlarda kolayca uygulanabilen mini sekanslama (SNaPshot) yöntemine dayalı olarak geliştirilmiştir. 34-plex dört büyük kıtasal popülasyonun ayrımını (Uzak Asya, Avrupa, Afrika ve Amerika) başarıyla yapabilmektedir (18, 22). Bu panel 2004 yılında Madrid'de meydana gelen "11-M Madrid bombalamaları" olarak bilinen terör olayının aydınlatılmasında kullanılmıştır. Biyolojik delillerden sadece 7 STR lokusu tiplendirilebil- 
miştir. Ancak bu STR lokuslarıyla ne şüphelilerle ne de DNA veri bankalarında bir eşleşme bulunamamıştır. 34plex ile yapılan biyocoğrafik soy analizi ile üç biyolojik örneğin Kuzey Afrika orijinli birine ait olabileceği ve bir örneğin ise Avrupalı birine ait olabileceği belirlenmiştir. İspanya ulusal DNA veri bankasında yapılan ailesel taramada bu örneğin Cezayir asıllı bir kişiden geldiği belirlenmiş ve soruşturmaya farklı bir yön vermiştir (23). mtDNA ve Y kromozomu markırlarıyla bu bilgiye ulaşılamamıştır.

Bugüne kadar geliştirilen hemen hemen tüm AISNPs panelleri genellikle kıtasal popülasyonların ayrımında kullanılmıştır. Tablo 1'de bu alanda geliştirilmiş başlıca AISNPs panelleri listelenmiştir. Bu panellerin birçoğu genellikle Amerika (Afro-Amerikalılar, Avrupa kökenli beyaz Amerikalılar, Hispanik Amerikalılar), Avrupa, Okyanusya, Asya ve Afrika popülasyonları gibi majör popülasyonların ayrımını hedeflemektedir (18, 24-26). Dolayısıyla geliştirilen panellerin çoğu dört veya beş ana kıtanın birbirinden ayrımında kullanılmaktadır. $\mathrm{Bu}$ AISNPs panellerinden en geniş kapsamlı olanı Kidd ve ark. $(19,27,28)$ tarafından geliştirilen 55 AISNPs paneli olup, bu panel tüm dünya popülasyonlarını en az on farklı popülasyon grubuna ayırabilmektedir. Bu panel güncel haliyle ülkemiz popülasyonu da dahil olmak üzere 164 dünya popülasyonunda çalışılmıştır (27-29). Türkiye'de AISNPs çalışmaları, SNP seçimi ve panel geliştirilmesi üzerine çeşitli araştırmalar bulunmaktadır (29-31). Bu çalıșmalardan Pakstis ve ark. tarafından yapılan çalışmada Türkiye popülasyonu 55 AISNPs paneli ile çalışılarak ilgili referans veri tabanında yer almıştır (http://frog.med. yale.edu/FrogKB). Böylece ülkemiz popülasyonu için biyocoğrafik soy tahmininin bu panel kullanılarak yapılabilmesi mümkün hale gelmiştir (28).

Adli bilimlerde kullanılacak AISNPs panelinin, tahmin edilecek soy bilgisinin güvenilir olması için uygun, seçici ve duyarlı bir AISNPs setinin kullanılması, aynı zamanda kıtasal ve bölgesel popülasyonları da kapsayacak ölçüde bir referans veri tabanına sahip olunması gerekmektedir $(15,19)$. Bu amaçla yapılan çalışmalar yukarıda belirtildiği gibi çoğunlukla kıtasal ayrım için olsa da k1talar arasında bulunan popülasyonları (Ortadoğu, Avrasya, Güney Asya, Batı Asya) diğer majör kıtasal popülasyonlardan ayırmaya yönelik çalışmalar da bulunmaktadır (17, 20, 29-31, 33, 39). Bu çalışmalardan biri Phillips ve ark.nın (2013) geliştirdiği ülkemizi de içine alan Avrasya bölgesinin Avrupa ve Uzak Doğu'dan ayrımını sağlayacak "Eurasiaplex" isimli AISNPs panelidir (20). Bu çalışmada CEPH-HGDP (Human Genome Diversity Project - Centre d'Étude du Polymorphisme Humain) referans örnekleri kullanılarak diğer popülasyonlar test edilmiş ve Asya, Avrupa, Afrika ve Avrasya (Merkez Güney Asya ve Ortadoğu'nun birlikte değerlendirildiği bölge) olmak üzere dört bölgenin diğerlerinden ayırımı gösterilmiştir.

Tablo 1. Adli genetik alanında geliştirilen başlıca AISNPs panelleri

\begin{tabular}{|c|c|c|c|c|}
\hline Panel Ad 1 & $\begin{array}{l}\text { SNP } \\
\text { say1s1 }\end{array}$ & SNP grubu & Yöntemi & Kaynak \\
\hline SNPforID 34-plex & 34 & AISNPs & $\mathrm{SNaPshot}{ }^{\circledR}$ & $\begin{array}{l}\text { Phillips ve ark. 2007, Fondevila ve } \\
\text { ark. } 2013(18,22)\end{array}$ \\
\hline 128-SNP & 128 & AISNPs & TaqMan & Kosoy ve ark. 2009 (21) \\
\hline 33-plex & 33 & AISNPs \& PISNPs & $\mathrm{SNaPshot} \AA$ & Bulbul ve ark. 2011, $2016(17,30)$ \\
\hline Eurasiaplex & 23 & AISNPs & $\mathrm{SNaPshot} \AA$ & Phillips ve ark. 2013 (20) \\
\hline 55 AISNPs panel & 55 & AISNPs & TaqMan & Kidd ve ark. (19) \\
\hline $\begin{array}{l}\text { EUROFORGEN Global } \\
\text { AIM-SNP }\end{array}$ & 128 & AISNPs & Sequenom iPLEX® (MPS) & Phillps et al. 2014 (25) \\
\hline 50-SNPs & 50 & AISNPs \& PISNPs & SNaPshot ${ }^{\circledR}$ & Gettings ve ark. 2013(32) \\
\hline Pacifiplex & 29 & AISNPs & SNaPshot ${ }^{\circledR}$ & Santos ve ark. 2016 (33) \\
\hline EurEas_Gplex & 14 & AISNPs & SNaPshot $\mathbb{R}$ & Daca-Roszak ve ark. 2016 (34) \\
\hline 27-plex SNP & 27 & AISNPs & $\mathrm{SNaPshot} \AA$ & Wei ve ark. 2016 (35) \\
\hline Global AIMs Nano & 31 & AISNPs & $\mathrm{SNaPshot} \AA$ & de la Puente ve ark. 2016 (36) \\
\hline $\begin{array}{l}\text { HID-Ion AmpliSeq } \\
\text { Ancestry Panel }\end{array}$ & 165 & AISNPs & Ion PGM (MPS) & Thermo Fisher Science $(19,21)$ \\
\hline $\begin{array}{l}\text { ForenSeq }{ }^{\mathrm{TM}} \text { DNA } \\
\text { Signature Prep Kit }\end{array}$ & 164 & $\begin{array}{l}\text { IISNPs \& AISNPs \& } \\
\text { PISNPs\& STRs }\end{array}$ & MiSeq FGx (MPS) & The Illumina ${ }^{\circledR}(37)$ \\
\hline 86 AISNPs panel & 86 & AISNPs & Taqman, MPS & Bulbul ve ark. $2018(31,38)$ \\
\hline
\end{tabular}


Ancak Ortadoğu bölgesinin daha iyi ayrılabilmesi için daha fazla AISNPs markırıyla ve referans örnek ile çalış1lması gerektiği önerilmiştir (20).

Toplumumuz genetik ve coğrafik olarak Ortadoğu, Avrupa ve Merkez Güney Asya popülasyonlarının arasında yer almaktadır. Bu yüzden Türkiye popülasyonun genetik yapısının incelenmesinde Ortadoğu, Avrupa ve Merkez Güney Asya popülasyonlarıyla olan genetik ilişkilerinin saptanması önemlidir. Konu ile ilgili ülkemizde yapılan araştırmada bu bölgeleri birbirinden ayırt edecek 33plex AISNPs paneli geliştirilmiştir $(17,30)$. Söz konusu çalışmada biyocoğrafik soy tahmininde 28 farklı (Avrupa, Afrika, Uzak Doğu, Merkez Güney Asya, Ortadoğu popülasyonları) popülasyon $\left(\mathrm{N}_{\text {toplam }}=1081\right)$ ile üç farklı AIM SNP seti (33plex, 34-plex ve Eurasiaplex) çalış1larak popülasyonlar arası genetik ilişkiler belirlenmiştir. 33plex ile Avrupa, Uzak Doğu ve Afrika kıtalarına ait popülasyonları başarıyla ayrılabilirken, Ortadoğu/Merkez Güney Asya popülasyonlarının birbirlerinden ayrımı kesin olarak yapılamamıştır. Bu araştırmada Türkiye popülasyonu; Avrupa, Merkez Güney Asya-Ortadoğu popülasyonları ile genetik benzerlik göstermiştir. Sonuç olarak 33plex, 34plex ve Eurasiaplex ile bir arada kullanıldıklarında çalışılan popülasyonlar arasındaki ayrımın arttığ1 görülmüştür $(17,30)$. Diğer bir araştırmada ise en yaygın kullanılan ve en fazla referans popülasyonuna sahip Kidd 55 AISNPs paneli çalışmış ve bulunduğumuz bölge ile ilgili bilgi verebilecek 32 AISNPs bölgesi seçilmiştir (29). Söz konusu çalışmada Doğu Afrika, Kuzey Afrika, Güney Batı Asya ve Güney Asya bölgeleri sadece 32 AISNPs kullanılarak ayırt edilebilmiştir. Bu çalışmaya ait bir Structure analizi aşağıda görülmektedir. Çalışmada Kidd 55 AISNPs paneli ve bunun bir alt grubu olarak 32 AISNPs markırı karşılaştırılmış ve bu coğrafik bölgeler için sadece 32 AISNPs kullanılabileceği belirtilmiştir (29).

Yine Türkiye popülasyonuna ait yapılan diğer bir araştırmada, Truelsen ve ark. Danimarka'da yaşayan 100 Türk'te, ticari bir kit olan Precision ID Ancestry Panel (Thermo Fisher Scientific) ile çalışmışlardır (40). $\mathrm{Bu}$ çalışmada yukarıda belirtildiği gibi kıtasal popülasyonların ayrımında kullanılan AISNPs bölgeleri (Kidd 55 AISNPs ve Seldin 128 AISNPs paneli) kullanılmış ve dünya popülasyonları ile karşılaştırma yapılarak, test edilen Türk popülasyonu İran ve diğer Avrupa ve Merkez Güney Asya popülasyonlarından ayrılamamıştır. Araştırıcılar bu popülasyonların Avrupa ve Merkez Güney Asya popülasyonlarından ayrılması için bu bölgeye özgü bir AISNP panelinin geliştirilmesi gerektiğini önermişlerdir (40).

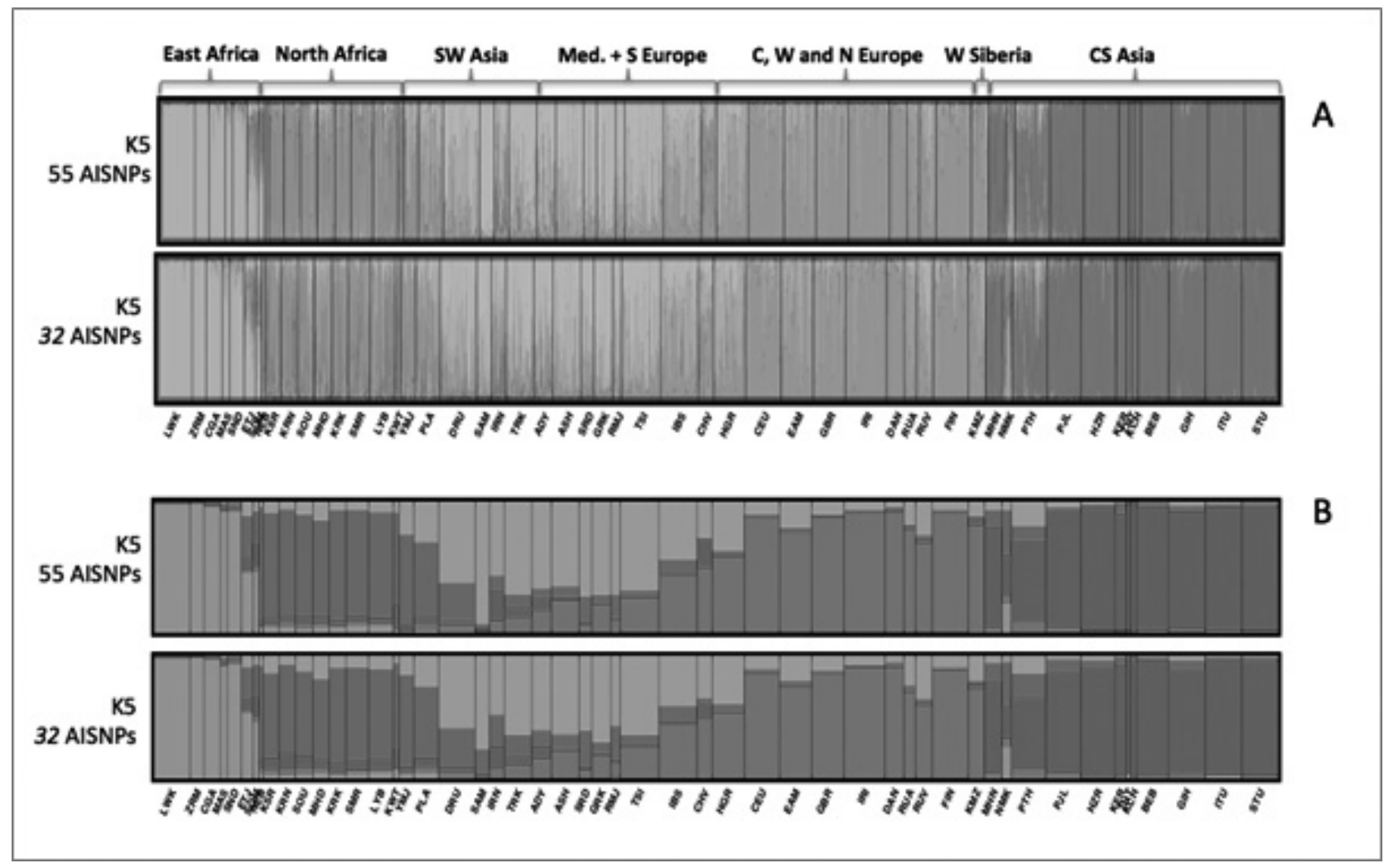

Şekil 1. Kidd 55 AISNPs ve bunun alt grubu olan 32 SNP kullanılarak yapılan Structure analizleri. A. Birey düzeyinde Structure sonucu B. Popülasyon düzeyinde Structure sonucu (29) 
Yapılan güncel bir çalışmada ise Kidd 55 AISNPs'de yer alan bölgelere ek olarak yine Uzak Batı Asya ve Akdeniz popülasyonlarının diğer popülasyonlarıdan ayrımında kullanılacak yeni 86 AISNPs markırları belirlenmiştir. Bu çalışmada, olay yerinden gelen bir delil ile yapılan ilk analizde Kidd 55 AISNPs panelinin çalışılmas1 ve bu panel ile elde edilen sonuç doğrultusunda eğer gerekli ise (yani elde edilen biyocoğrafik soy tahmini Avrasya ve Kuzey Afrika'yı işaret ediyor ise) daha detaylı ve doğru biyocoğrafik soy tahmini için bu bölgelere özgün geliştirilen panellerin kullanılması hedeflenmiştir. Böylece Kidd 55 AISNPs analizinden sonra Güney Batı Asya, Akdeniz bölgeleri için seçilmiş 86 AISNPs paneli kullanılarak daha yüksek olasılık oranlarında ve doğrulukta biyocoğrafik soy tayini yapılabilmektedir (Bulbul, Speed et al. 2018). Tablo 2'de bu araştırmaya ait iki panel ile test edilen aynı bireyin biyocoğrafik soy tahmini gösterilmiştir.
Diğer bir iki basamaklı soy tayini AISNPs paneli olarak geliştirilen ve Uzak Doğu Asya popülasyonlarının detaylı ayrımlarında kullanılması hedeflenen 74 AISNPs panelidir. Bu araştırmada da iki basamaklı biyocoğrafik soy tahmin yöntemi kullanılmış ve diğer çalışmalardan farklı olarak Güneybatı Asya, Kuzey Asya ve Uzak Doğu olarak Asya popülasyonları üç farklı gruba ayrılabilmiştir (39).

\section{SNP Analiz Yöntemleri}

Adli amaçlı geliştirilen ilk SNP panelleri geçtiğimiz on y1l boyunca genellikle mini sekanslama yöntemine dayalı olarak yapılmıştır. Mini sekanslama reaksiyonunda primer istenilen SNP markırına komşu olacak şekilde hedef diziye bağlanır ve hedef SNP tek bir işaretli dideoksiribonükleosit trifosfat (ddNTP) ile uzatılır. ddNTP 3'OH grubuna sahip olmadığından DNA polimeraz enziminin zincire yeni bir nükleotid eklemesine engel olur

Tablo 2. Kidd 55 AISNPs paneli ve 86 AISNPs paneli ile yapılan biyocoğrafik soy tahmini. En başta listelenen ilk 20 popülasyon gösterilmiştir.

\begin{tabular}{|c|c|c|c|c|c|}
\hline \multicolumn{3}{|c|}{$\begin{array}{c}\text { Kidd } 55 \text { AISNPs paneli } \\
164 \text { referans popülasyon ile test edilmiştir }\end{array}$} & \multicolumn{3}{|c|}{$\begin{array}{l}86 \text { AISNPs paneli } \\
39 \text { referans popülasyon ile test edilmiştir }\end{array}$} \\
\hline $\begin{array}{l}\text { Popülasyon (Bölge ve örnek } \\
\text { sayısı 2N) }\end{array}$ & $\begin{array}{c}\text { Her bir } \\
\text { popülasyondaki } \\
\text { Olasılık }\end{array}$ & $\begin{array}{c}\text { LR } \\
\text { (Olasılık } \\
\text { Oranı) } \\
\end{array}$ & $\begin{array}{l}\text { Popülasyon (Bölge ve örnek } \\
\text { sayısı 2N) }\end{array}$ & $\begin{array}{c}\text { Her bir } \\
\text { popülasyondaki } \\
\text { Olasılık }\end{array}$ & $\begin{array}{c}\text { LR } \\
\text { (Olasılık } \\
\text { Oranı) }\end{array}$ \\
\hline İranlilar $($ Asya,88) & $1.26 E-13$ & & Türkler (Asya,154) & $5,32 E-33$ & \\
\hline Sardinyalılar (Avrupa,68) & $1.72 E-14$ & 7.32 & Iranlılar (Asya,88) & $2,13 E-33$ & 2,50 \\
\hline Türkler (Asya,154) & $1.41 E-14$ & 8.93 & Sardinyalılar (Avrupa,68) & $5,25 \mathrm{E}-34$ & 10,10 \\
\hline İranlılar (Asya,186) & $1.22 \mathrm{E}-14$ & 10.3 & Kıbrıslı Türkler (Avrupa,120) & $4,60 \mathrm{E}-34$ & 11,60 \\
\hline Kibrislı Rumlar (Avrupa,190) & $1.08 \mathrm{E}-14$ & 11.6 & Batı Çerkesleri (Avrupa,108) & $2,76 \mathrm{E}-34$ & 19,30 \\
\hline Türkler (Asya,200) & $9.77 \mathrm{E}-15$ & 12.9 & Dürziler (Asya,212) & $1,70 \mathrm{E}-34$ & 31,40 \\
\hline $\begin{array}{l}\text { Kuzey Irak Arapları } \\
(\text { Asya,260) }\end{array}$ & 4.12E-15 & 30.6 & İberyalılar (IBS)(Avrupa,214) & $9,04 \mathrm{E}-35$ & 58,90 \\
\hline Kildaniler (Asya,44) & $3.83 \mathrm{E}-15$ & 32.9 & $\begin{array}{l}\text { Avrupalı Museviler } \\
\text { (Avrupa,54) }\end{array}$ & $7,66 \mathrm{E}-35$ & 69,50 \\
\hline Yezidiler (Asya,298) & $3.44 \mathrm{E}-15$ & 36.7 & $\begin{array}{l}\text { Toskanalılar (TSI) } \\
\text { (Avrupa,214) }\end{array}$ & $3,46 \mathrm{E}-35$ & 154,00 \\
\hline $\begin{array}{l}\text { Avrupalı Museviler } \\
\text { (Avrupa,54) }\end{array}$ & $3.25 \mathrm{E}-15$ & 38.8 & Filistin Arapları (Asya,140) & $3,44 \mathrm{E}-35$ & 155,00 \\
\hline Kürtler (Asya,296) & $3.19 \mathrm{E}-15$ & 39.5 & $\begin{array}{l}\text { Aşkenazlar } \\
\text { (Avrupa,166) }\end{array}$ & $8,77 \mathrm{E}-36$ & 607,00 \\
\hline Şabaklar (Asya,18) & $3.18 \mathrm{E}-15$ & 39.6 & Kuveyt (Asya,32) & $1,22 \mathrm{E}-36$ & 4350,00 \\
\hline Kıbrıslı Türkler (Avrupa,120) & $2.82 \mathrm{E}-15$ & 44.7 & Yemen Musevileri (Asya,146) & $4,35 \mathrm{E}-38$ & $1,22 \mathrm{E}+05$ \\
\hline Süryaniler (Asya,250) & $2.67 \mathrm{E}-15$ & 47.1 & Rumlar (Avrupa,104) & $4,18 \mathrm{E}-38$ & $1,27 \mathrm{E}+05$ \\
\hline Türkmenler (Asya,258) & $2.25 \mathrm{E}-15$ & 55.9 & $\begin{array}{l}\text { Karışık Avrupalılar } \\
\text { (Avrupa,190) }\end{array}$ & $1,67 \mathrm{E}-38$ & $3,19 \mathrm{E}+05$ \\
\hline Batı Çerkesleri (Avrupa,108) & $9.56 \mathrm{E}-16$ & 132 & Çuvaşlılar (Avrupa,84) & $1,26 \mathrm{E}-38$ & $4,23 \mathrm{E}+05$ \\
\hline Dürziler (Asya,212) & $7.70 \mathrm{E}-16$ & 164 & Gujaratlar (GIH) (Asya,206) & $8,62 \mathrm{E}-39$ & $6,17 \mathrm{E}+05$ \\
\hline Rumlar (Avrupa,104) & $4.69 \mathrm{E}-16$ & 269 & Punjaplar (PJL) (Asya, 192) & $4,80 \mathrm{E}-39$ & $1,11 \mathrm{E}+06$ \\
\hline Aşkenazlar (Avrupa,166) & $3.14 \mathrm{E}-16$ & 401 & Ruslar (Avrupa,96) & $1,38 \mathrm{E}-40$ & $3,86 \mathrm{E}+07$ \\
\hline İberyalılar (IBS) (Avrupa,214) & $2.60 \mathrm{E}-16$ & 484 & Keralite(Asya,60) & $4,90 \mathrm{E}-41$ & $1,09 \mathrm{E}+08$ \\
\hline
\end{tabular}

(URL: http://frog.med.yale.edu web erişim tarihi:11/2018) 
ve sadece tek baz uzaması sağlanır. Rutin adli bilimler genetik laboratuvarlarında PCR ve kapiller elektroforez cihazı bulunduğundan, daha çok elektroforez ve floresan tespitine dayalı ticari SNaPshot ${ }^{\circledR}$ Multiplex Kit yöntemi kullanılmaktadır. Bunun için ticari olarak yaygın kullanılan SNaPshot ${ }^{\circledR}$ Multiplex Kiti (Thermo Fisher Scientific) ile en fazla 35 SNP'ye kadar çok sayıda lokusun bir arada analiz edilmesi mümkündür $(41,42)$.

Her ne kadar mini sekanslama yönteminin birçok avantajı olmasına rağmen gelişen teknoloji ile birlikte bu yönteminin yanı sıra yeni nesil dizi analizi cihazları (NGS, Next Generation Sequencing) daha güncel teknolojik tanımıyla kitlesel paralel dizileme (MPS, Massive Parallel Sequencing) kullanılmaya başlanmıştır. MPS yöntemi son yıllarda adli bilimlerde geleceğin teknolojisi olarak kullanılmaya başlanmış olup bu yöntemin 30 yıldan beri kullanılan klasik PCR- kapiller elektroforez yönteminin yerini alacağı düşünülmektedir. MPS'in en önemli avantajlarından biri; PCR-kapiller elektroforez (KE) ile tek seferde sadece bir markır sistemi analiz edilebilirken (örneğin sadece bir SNP paneli), MPS ile aynı anda çok sayıda ve farklı markır sistemlerinin (STR, SNP, Indel gibi) analizi yapılabilmektedir. Böylece olay yerinden gelen az miktardaki DNA delilinden tek bir iş akışında çok daha fazla bilgi edinilebilmektedir. MPS ile ilgili ticari firmalar ve araştırıcılar tarafından geliştirilen yeni MPS panelleri bulunmaktadır. Bu paneller çok sayıda markırın (100-200) tek sistem içinde tiplendirilmesine olanak sağlamaktadır. Adli bilimlerde en iyi bilinen ve MPS cihazlarına da adapte edilen SNP panellerinin başında Seldin 128 AISNPs, Kidd 55 AISNPs SNPforID 34-plex, Irisplex ve HirisPlex PISNPs (Fenotip SNP markırları, Phenotypic-Informative SNP) panelleri gel- mektedir $(18,19,21,43,44)$. SNP panellerinin tek başına bulunduğu paneller (Thermo Fisher Scientific- Precision ID Ancestry Panel Ancestry Paneli gibi) olduğu gibi diğer markır sistemleriyle birlikte bulunan paneller de (The Illumina ${ }^{\circledR}$ ForenSeq ${ }^{\mathrm{TM}}$ DNA Signature Prep Kit gibi) ticari olarak piyasada bulunmaktadır. Her iki ticari MPS panelinde de (Thermo Fisher Scientific ve The Illumina ${ }^{\circledR}$ ) biyocoğrafik soy paneli olarak Kidd 55 ve Seldin 128 AISNP panelleri bulunmaktadır. Aynı zamanda ticari olmayan ve araştırıcılar tarafından geliştirilen SNP panelleri de bulunmaktadir $(25,26,38,45)$. EUROFORGEN Global AIM-SNP paneli bu panellerden biri olup, bir Avrupa Birliği projesi çerçevesinde geliştirilmiştir. Global AIM-SNP panelinde pek çok SNP panelinden seçilmiş 128 SNP'den oluşan, beş kıtasal popülasyonun ayrımında kullanılmak üzere tasarlanmıştır (25). MPS sistemi ile ülkemizde yapılan bir çalışmada ise biyocoğrafik soy ve fenotip SNP markırlarından oluşan yeni bir panel (moleküler görgü tanıklığı) geliştirilmiştir (38). Bu çalışmada Kidd 55, 86 AISNPs ve göz, saç ve ten rengi PISNPs markırlarını içeren 186 SNP den oluşan bir panel geliştirilmiştir (38). Bu panel ile Türkiye'de faile ulaşılamayan ve aydınlatılamayan adli vakalarda delilden suçluya giderken adli sürecin daha hızlı işlemesine ve olguların çözümüne büyük katkı sağlayacağı düşünülmektedir.

\section{Biyocoğrafik Soy Tahmininde Kullanılan İstatistiksel Yöntemler}

AISNPs markırları biyocoğrafik soy analizinde popülasyon genetiğine dayalı metotlarla bir kişinin hangi popülasyon veya popülasyon gruplarına dahil olduğu, alel frekanslarının popülasyonlar arası karşılaştırılmasıyla

Şekil 2. SNIPPER programı ile analiz edilen bir örnek sonucu

Executing the query with 5 populations and the 34plexprevious SNP-Indels of the individual to classify: AAAACTGGCCAATTCCAACCCCAGTTGGAAAAAGCCTTTTGGTTCCCTCGCCAGACTTCCCTGTCCAG

\begin{tabular}{|c|c|c|}
\hline AFRICA & $\$ 8.268765$ & $0.00 \%$ \\
\hline \hline EUROPE & 24.099341 & $\$ 9.24 \%$ \\
\hline \hline EAST_ASIA & 53.186371 & $0.00 \%$ \\
\hline \hline OCEANIA & 64.758237 & $0.00 \%$ \\
\hline AMIERICA & 46.931825 & $0.00 \%$ \\
\hline
\end{tabular}

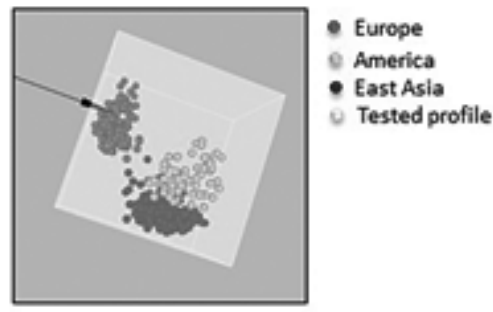

This profile is more than a billion $\left(10^{\circ}\right)$ times more likely EUROPE than AMERICA, and more than a billion $\left(10^{\circ}\right)$ times more likely EUROPE than EAST_ASIA. Predicted admixture: $100.00 \%$ for EUROPE; $0.00 \%$ for AMERICA; $0.00 \%$ for EAST_ASIA.

Therefore, the profile should be EUROPE.

(http://mathgene.usc.es/cgi-bin/snps/processdefault5pops.cgi web erişim tarihi 11/2018) 
tayin edilir. Bunun için; Structure analizi, PCA (Principal Component Analysis-Temel Bileșenler Analizi), Bayes teoremi olabilirlik oranını (Likelihood Ratio, LR) hesaplayan FROG-kb, Snipper gibi analiz programları kullanılmaktadır $(20,46,47)$. Bu analizlerin güvenilirliği karşılaştırılan popülasyonların büyüklüğüne, test edilen markır sayısına, markırın soy bilgilendirme değerine ve test edilen kişinin karışım derecesine bağlıdır $(48,49)$.

AISNPs analizlerinde özellikle adli bilimler de kullanılmak üzere geliştirilmiş kişi bazında analize imkan veren iki analiz yöntemi bulunmaktadır. Bunlardan ilki Phillips ve ark. tarafından geliştirilen bir web uygulaması olup, LR istatistiği uygulayarak bilinmeyen bir örneğin bilinen farklı biyocoğrafik orijinli referans örnekleri ile karşılaştırılması esasına dayanan Snipper programıdır. $\mathrm{Bu}$ programda, belirli AISNPs panellerinde çalışılan ve referans popülasyon olarak alınan veriler ile araştırılacak kişinin ya da olay yerinden gelen ve bilinmeyen delilin profili sisteme girildiğinde önceden programa yüklenmiş olan bu veri setindeki popülasyonlardan hangisine ait olabileceği şeklinde olabilirlik oranı hesaplanır (18). Ayrıca yeni geliştirilen bir SNP paneli için de uygun bir referans veri seti yüklenerek LR hesaplanması mümkündür. $\mathrm{Bu}$ da programın en büyük avantajlarından biridir (50). Aşağıda Snipper programı kullanılarak bir örneğin 34-plex ile analiz sonucu verilmiştir.

$\mathrm{Bu}$ programda beș farklı ana kıta içinde sorgulanan örneğin/kişinin en yakın ve benzer olabileceği popülasyon grubu belirlenmektedir. Test edilen bireyin "Avrupal olması Amerikalı (Amerika kitası) ve Uzak Doğulu olmasindan dokuz milyar $\left(10^{9}\right) \mathrm{kez}$ daha olasidır ve Okyanusyalı ve Afrikalı olma olasılı̆̆ ise diğer olasılıklardan çok daha düşüktür" olarak yorumlanabilir. Dolayısıyla bu kişinin Avrupa popülasyonuna çok daha benzer olduğu söylenebilmektedir. Test edilen bireyin beş referans popülasyon içinden en yakın olduğu üç popülasyon bireyleri (Avrupa, Amerika ve Uzak Doğu) ile üç boyutlu PCA analizi de programda verilmektedir. Bu analizde de sarı ile işaret edilen test profilinin (Şekil 2. Sağdaki 3 boyutlu grafik) Avrupa popülasyonuna ait bireylerle birlikte gruplandığı görülmektedir.

Adli bilimler uygulamaları için geliştirilmiş diğer bir istatistiksel analiz programı olan online FROG-kb uygulamasıdır. Bu uygulamada da Bayes teoremi olabilirlik oranı istatistiği uygulayarak bilinmeyen bir örneğin bilinen farklı biyocoğrafik orijinli referans örnekleri ile karşılaştırılması esasına dayanır. FROG-kb programa uygun bir referans veri setine bağlı kalarak araştırılacak bireyin ya da delilin profili sisteme girildiğinde önceden programa yüklenmiş olan veri setindeki popülasyonlardan hangisine ait olabileceği olasılığı hesaplanır $(47,48)$. Bu hesaplamalarda FROG-kb için kişilerin genotipi sisteme girilerek seçilen panelde kişinin olası popülasyonlar ve/ veya popülasyon grubu belirlenir. FROG-kb hesaplamalarında sistem içinde bulunan ilgili panelin test edildiği popülasyonların alel frekansları yer almaktadır. Elde edilen sonuçlar bir popülasyon listesi şeklinde olup olasılığı en yüksek popülasyondan en düşük popülasyon olacak şekilde sıralanmaktadır $(47,48)$.

Tablo 2'de bir örneğin/kişinin Frog-kb ile biyocoğrafik soy analizi popülasyon düzeyindeki olasılık hesaplamaları online olarak yapılmıştır. Analizlerde kullanılan referans popülasyon sayısı Kidd 55 AISNPs paneli için 164 popülasyon ve 86 AISNPs paneli için 39 popülasyondur. Tablonun sol tarafinda Kidd 55 AISNPs panelinin, sağ tarafinda ise 86 AISNPs panelinin en yüksek olasılık gösteren ilk yirmi popülasyonu sıralanmıştır. LR değeri 10 ve altında olan popülasyonlar, kişinin gelmiş olabileceği soyu en iyi tahmin eden bölgeler olduğu için koyu olarak işaretlenmiştir. Bu tahminin yorumlanmasında oldukça önemlidir, çünkü istatistiksel olarak LR 10'a kadar olan tüm popülasyonlar birbiriyle aynı sonucu verecek kadar yakındır. Dolayısıyla sonuçlar değerlendirilirken en yüksek olasıllıklı popülasyon değil, istatistiksel olarak (en büyük basamaklı) basamaksal büyüklüğü 10 ve 10 'nun altında (one order of magnitute) olan popülasyonlar birlikte değerlendirilir. Ayrıca, birbirine yakın popülasyonların alel frekanslarının birbirine benzerlik göstermesi de olasıdır. Dolasıyla aynı coğrafik bölgelerde bulunan popülasyonların alel frekansları benzer olduğu için olasılık oranları da benzer olabilir. Böylece yorum yapılırken kişinin ilk listelenen popülasyondan gelmiş olabileceği değil; kişinin soy bilgisinin gelmiş olabileceği coğrafik bölgenin tahmini yapılmalıdır $(28,29,31)$. $\mathrm{Bu}$ örnekte Türkiye popülasyonuna ait bir kişinin her iki panel ile çalışılması sonucunda (Tablo 2); bu kişinin Kidd 55 AISNPs paneli çalışıldığında Güney Batı Asya ve Akdeniz bölgesinden gelen bir kişi olduğu tahmin edilebilirken, 86 AISNPs paneli ile daha da özgün olarak bu kişinin soyunun yüksek olasılıkla Güney Batı Asya bölgesinden gelmiş olabileceği söylenebilir.

Kişiye ait fiziksel özelliklerin veya atasal soyun bilinmesinin etik yönü de tartışılmaktadır. Elde edilecek bilgiler kişiye özgü değildir sadece şüpheli grubunu daraltarak soruşturmaya yön verebilecek yardımcı bir uygulamadır. AISNPs markırlarının pek çoğu DNA'nın kodlama yapmayan bölgelerinde veya genler arası bölgelerde bulunan ve değişik coğrafik bölgelerde farklı alel frekansları gösteren markırlardır $(9,19)$.

Biyocoğrafik soy analizleri ile ilgili bazı ülkelerde özel yasal düzenlemeler bulunurken (Hollanda gibi), bazı ülkelerde (ABD, İspanya, İngiltere gibi) herhangi bir ya- 
sal düzenleme olmadan uygulamalar yapılmakta, bazı ülkelerde ise (Belçika, Almanya gibi) kullanılmamaları ile ilgili kesin yargı kararları bulunmaktadır $(51,52)$. Ülkemizde ise AISNPs markırlarının kullanılmasıyla ilgili özel bir yasal düzenleme bulunmamaktadır. 2004 tarihli ve 5271 sayll Ceza Muhakemesi Kanununun 82. maddesine dayanılarak hazırlanan Ceza Muhakemesinde Beden Muayenesi, Genetik İncelemeler ve Fizik Kimliğin Tespiti Hakkında Yönetmelik, günümüzdeki teknolojik ve bilimsel olarak gelinen nokta düşünüldüğünde güncelliğini yitirmiştir. Dolayısıyla ülkemizde de adalet sistemine büyük katkılar sağlayacak bu tür markırlarla (AISNPs, PISNPs gibi) ve geliştirilen yeni teknikler ile ilgili gerekli hukuki açılımların yapılması gerekmektedir.

\section{Sonuç}

İnsan biyolojisi ile ilgili yeni bilgiler, yeni nesil yüksek verimli genom teknolojileri ve gelişmiş biyoinformatik testler insan DNA'sının ve popülasyonların genetik yapılarının daha iyi anlaşılmasına olanak vermiștir. Bu yeni bilgiler birçok alanda olduğu gibi adli genetik alanında da kullanılmaktadır. Bu alandaki uygulamalarda özellikle sorușturma aşamasında șüphelinin bulunamadığı durumlarda faile ait olduğu düşünülen herhangi bir biyolojik delilden (kan lekesi, semen tükürük gibi) kişinin dış görünüşüne ait fikir verebilecek herhangi bir bilginin bulunması soruşturmanın aydınlatılması açısından oldukça önemlidir. Faile ulaşılamayan ve çözümsüz kalan olgularda hem soruşturmaya yön vermek hem de olayın hızlı bir şekilde aydınlatılabilmesine katkı sağlamak amacıyla geliştirilen markır setleri ile bir kişinin biyocoğrafik soyu tahmin edilebilmektedir. Ülkemizin bulunduğu coğrafyayla ilgili pek çok AISNPs çalışılmış durumdadır. Bu panellerin yakın gelecekte adli uygulamalarda rutinde kullanılacağı öngörülmektedir. Böylece AISNPs kullanılması Türkiye'de faile ulaşılamayan ve aydınlatılamayan adli vakalarda delilden suçluya giderken adli sürecin daha hızlı işlemesine ve olguların çözümüne büyük katkı sağlayacaktır.

\section{Kaynaklar}

1. Butler JM, Coble MD, Vallone PM. STRs vs. SNPs: thoughts on the future of forensic DNA testing. Forensic science, medicine, and pathology. 2007;3(3):200-5. DOI: https:// doi.org/10.1007/s12024-007-0018-1

2. Budowle B, van Daal A. Forensically relevant SNP classes. BioTechniques. 2008;44(5):603-8, DOI: https://doi.org/10. 10.2144/000112806

3. Butler JM, Budowle B, Gill P, Kidd KK, Phillips C, Schneider PM, et al. Report on ISFG SNP Panel Discussion. Forensic Science International: Genetics Supplement Series. 2008;1(1):471-2. DOI: https://doi.org/10.1016/j. fsigss.2007.10.159
4. Gill P. An assessment of the utility of single nucleotide polymorphisms (SNPs) for forensic purposes. International journal of legal medicine. 2001;114(4-5):204-10.

5. Race E, Genetics Working G. The use of racial, ethnic, and ancestral categories in human genetics research. American journal of human genetics. 2005;77(4):519-32. DOI: https:// doi.org/10.1086/491747

6. Bonilla C, Shriver MD, Parra EJ, Jones A, Fernandez JR. Ancestral proportions and their association with skin pigmentation and bone mineral density in Puerto Rican women from New York city. Human genetics. 2004;115(1):57-68. DOI: https://doi.org/10.1007/s00439-004-1125-7

7. Tishkoff SA, Kidd KK. Implications of biogeography of human populations for 'race' and medicine. Nature genetics. 2004;36(11 Suppl):S21-7. DOI: https://doi.org/10.1038/ ng1438

8. Butler K, Peck M, Hart J, Schanfield M, Podini D. Molecular "eyewitness": Forensic prediction of phenotype and ancestry. Forensic Science International: Genetics Supplement Series. 2011;3(1):e498-e9. DOI: https://doi.org/10.1016/j. fsigss.2011.09.109

9. Kayser M. Forensic DNA Phenotyping: Predicting human appearance from crime scene material for investigative purposes. Forensic science international Genetics. 2015;18:3348. DOI: https://doi.org/10.1016/j.fsigen.2015.02.003

10. Rosenberg NA, Li LM, Ward R, Pritchard JK. Informativeness of genetic markers for inference of ancestry. American journal of human genetics. 2003;73(6):1402-22. DOI: https://doi.org/10.1086/380416

11. Phillips C, Fernandez-Formoso L, Gelabert-Besada M, Garcia-Magarinos M, Santos C, Fondevila M, et al. Development of a novel forensic STR multiplex for ancestry analysis and extended identity testing. Electrophoresis. 2013;34(8):1151-62. DOI: https://doi.org/10.1002/ elps.201200621

12. Algee-Hewitt BF, Edge MD, Kim J, Li JZ, Rosenberg NA. Individual Identifiability Predicts Population Identifiability in Forensic Microsatellite Markers. Current biology : CB. 2016;26(7):935-42. DOI: https://doi.org/10.1016/j. cub.2016.01.065

13. Halder I, Shriver M, Thomas M, Fernandez JR, Frudakis T. A panel of ancestry informative markers for estimating individual biogeographical ancestry and admixture from four continents: utility and applications. Human mutation. 2008;29(5):648-58. DOI: https://doi.org/10.1002/humu.20695

14. Frudakis T, Venkateswarlu K, Thomas MJ, Gaskin Z, Ginjupalli S, Gunturi S, et al. A classifier for the SNPbased inference of ancestry. Journal of forensic sciences. 2003;48(4):771-82.

15. Phillips C. Forensic genetic analysis of bio-geographical ancestry. Forensic science international Genetics. 2015;18:4965. DOI: https://doi.org/10.1016/j.fsigen.2015.05.012

16. Shriver MD, Parra EJ, Dios S, Bonilla C, Norton H, Jovel $\mathrm{C}$, et al. Skin pigmentation, biogeographical ancestry and admixture mapping. Human genetics. 2003;112(4):387-99. DOI: https://doi.org/10.1007/s00439-002-0896-y 
17. Bulbul O, Filoglu G, Altuncul H, Aradas AF, Ruiz Y, Fondevila M, et al. A SNP multiplex for the simultaneous prediction of biogeographic ancestry and pigmentation type. Forensic Science International: Genetics Supplement Series. 2011;3(1):e500-e1. DOI: https://doi.org/10.1016/j. fsigss.2011.10.001

18. Phillips C, Salas A, Sanchez JJ, Fondevila M, Gomez-Tato A, Alvarez-Dios J, et al. Inferring ancestral origin using a single multiplex assay of ancestry-informative marker SNPs. Forensic science international Genetics. 2007;1(3-4):27380. DOI: https://doi.org/10.1016/j.fsigen.2007.06.008

19. Kidd KK, Speed WC, Pakstis AJ, Furtado MR, Fang R, Madbouly A, et al. Progress toward an efficient panel of SNPs for ancestry inference. Forensic science international Genetics. 2014;10:23-32. DOI: https://doi.org/10.1016/j. fsigen.2014.01.002

20. Phillips C, Freire Aradas A, Kriegel AK, Fondevila M, Bulbul O, Santos C, et al. Eurasiaplex: a forensic SNP assay for differentiating European and South Asian ancestries. Forensic science international Genetics. 2013;7(3):359-66. DOI: https://doi.org/10.1016/j.fsigen.2013.02.010

21. Kosoy R, Nassir R, Tian C, White PA, Butler LM, Silva $\mathrm{G}$, et al. Ancestry informative marker sets for determining continental origin and admixture proportions in common populations in America. Human mutation. 2009;30(1):6978. DOI: https://doi.org/10.1002/humu.20822

22. Fondevila M, Phillips C, Santos C, Freire Aradas A, Vallone PM, Butler JM, et al. Revision of the SNPforID 34-plex forensic ancestry test: Assay enhancements, standard reference sample genotypes and extended population studies. Forensic science international Genetics. 2013;7(1):63-74. DOI: https://doi.org/10.1016/j.fsigen.2012.06.007

23. Phillips C, Prieto L, Fondevila M, Salas A, Gomez-Tato A, Alvarez-Dios J, et al. Ancestry analysis in the 11-M Madrid bomb attack investigation. PloS one. 2009;4(8):e6583. DOI: https://doi.org/10.1371/journal.pone.0006583

24. Nassir R, Kosoy R, Tian C, White PA, Butler LM, Silva G, et al. An ancestry informative marker set for determining continental origin: validation and extension using human genome diversity panels. BMC genetics. 2009;10:39. DOI: https://doi.org/10.1186/1471-2156-10-39

25. Phillips C, Parson W, Lundsberg B, Santos C, Freire-Aradas A, Torres $\mathrm{M}$, et al. Building a forensic ancestry panel from the ground up: The EUROFORGEN Global AIM-SNP set. Forensic science international Genetics. 2014;11:13-25. DOI: https://doi.org/10.1016/j.fsigen.2014.02.012

26. Mehta B, Daniel R, Phillips C, Doyle S, Elvidge G, McNevin D. Massively parallel sequencing of customised forensically informative SNP panels on the MiSeq. Electrophoresis. 2016;37(21):2832-40. DOI: https://doi.org/10.1002/ elps.201600190

27. Pakstis AJ, Kang L, Liu L, Zhang Z, Jin T, Grigorenko $\mathrm{EL}$, et al. Increasing the reference populations for the 55 AISNP panel: the need and benefits. International journal of legal medicine. 2017;131(4);913-917 DOI: https://doi. org/10.1007/s00414-016-1524-Z
28. Pakstis AJ, Haigh E, Cherni L, ElGaaied ABA, Barton A, Evsanaa B, et al. 52 Additional Reference Population Samples for the 55 AISNP panel. Forensic Sci Int Genet. 2015;(19):269-271. DOI: https://doi.org/10.1016/j.fsigen.2015.08.003

29. Bulbul O, Cherni L, Khodjet-El-Khil H, Rajeevan H, Kidd KK. Evaluating a subset of ancestry informative SNPs for discriminating among Southwest Asian and circum-Mediterranean populations. Forensic science international Genetics. 2016;23:153-8. DOI: https://doi.org/10.1016/j.fsigen.2016.04.010

30. Bulbul O, Filoglu G, Zorlu T, Altuncul H, Freire-Aradas A, Sochtig $\mathrm{J}$, et al. Inference of biogeographical ancestry across central regions of Eurasia. International journal of legal medicine. 2016;130(1):73-9. DOI: https://doi.org/10.1007/ s00414-015-1246-7

31. Bulbul O, Speed WC, Gurkan C, Soundararajan U, Rajeevan H, Pakstis AJ, et al. Improving ancestry distinctions among Southwest Asian populations. Forensic science international Genetics. 2018;35:14-20. DOI: https://doi. org/10.1016/j.fsigen.2018.03.010

32. Gettings KB, Lai R, Johnson JL, Peck MA, Hart JA, Gordish-Dressman H, et al. A 50-SNP assay for biogeographic ancestry and phenotype prediction in the U.S. population. Forensic science international Genetics. 2014;8(1):101-8. DOI: https://doi.org/10.1016/j.fsigen.2013.07.010

33. Santos C, Phillips C, Fondevila M, Daniel R, van Oorschot RA, Burchard EG, et al. Pacifiplex: an ancestry-informative SNP panel centred on Australia and the Pacific region. Forensic science international Genetics. 2016;20:71-80. DOI: https://doi.org/10.1016/j.fsigen.2015.10.003

34. Daca-Roszak P, Pfeifer A, Zebracka-Gala J, Jarzab B, Witt M, Zietkiewicz E. EurEAs_Gplex--A new SNaPshot assay for continental population discrimination and gender identification. Forensic science international Genetics. 2016;20:89100. DOI: https://doi.org/10.1016/j.fsigen.2015.10.004

35. Wei YL, Wei L, Zhao L, Sun QF, Jiang L, Zhang T, et al. A single-tube 27-plex SNP assay for estimating individual ancestry and admixture from three continents. International journal of legal medicine. 2016;130(1):27-37. DOI: https:// doi.org/10.1007/s00414-015-1183-5

36. de la Puente M, Santos C, Fondevila M, Manzo L, Consortium EU-N, Carracedo A, et al. The Global AIMs Nano set: A 31-plex SNaPshot assay of ancestry-informative SNPs. Forensic science international Genetics. 2016;22:81-8. DOI: https://doi.org/10.1016/j.fsigen.2016.01.015

37. Churchill JD, Schmedes SE, King JL, Budowle B. Evaluation of the Illumina((R)) Beta Version ForenSeq DNA Signature Prep Kit for use in genetic profiling. Forensic science international Genetics. 2016;20:20-9. DOI: https://doi. org/10.1016/j.fsigen.2015.09.009

38. Bulbul O, Filoglu G. Development of a SNP panel for predicting biogeographical ancestry and phenotype using massively parallel sequencing. Electrophoresis. 2018;39(21):2743-51. DOI: https://doi.org/10.1002/ elps. 201800243 
39. Li CX, Pakstis AJ, Jiang L, Wei YL, Sun QF, Wu H, et al. A panel of 74 AISNPs: Improved ancestry inference within Eastern Asia. Forensic science international Genetics. 2016;23:101-10. DOI: https://doi.org/10.1016/j.fsigen.2016.04.002

40. Truelsen DM, Farzad MS, Mogensen HS, Pereira V, Tvedebrink T, Børsting C, et al. Typing of two Middle Eastern populations with the Precision ID Ancestry Panel. Forensic Sci Int Genet Suppl Ser. 2017;6:e301-e2. DOI: https://doi. org/10.1016/j.fsigss.2017.09.133

41. Sobrino B, Brion M, Carracedo A. SNPs in forensic genetics: a review on SNP typing methodologies. Forensic Sci Int. 2005;154(2-3):181-94. DOI: https://doi.org/10.1016/j. forsciint.2004.10.020

42. Mehta B, Daniel R, Phillips C, McNevin D. Forensically relevant $\mathrm{SNaPshot}(\mathrm{R})$ assays for human DNA SNP analysis: a review. International journal of legal medicine. 2017;131(1):21-37. DOI: https://doi.org/10.1007/s00414016-1490-5

43. Walsh S, Liu F, Wollstein A, Kovatsi L, Ralf A, KosiniakKamysz A, et al. The HIrisPlex system for simultaneous prediction of hair and eye colour from DNA. Forensic science international Genetics. 2013;7(1):98-115. DOI: https:// doi.org/10.1016/j.fsigen.2012.07.005

44. Walsh S, Liu F, Ballantyne KN, van Oven M, Lao O, Kayser M. IrisPlex: a sensitive DNA tool for accurate prediction of blue and brown eye colour in the absence of ancestry information. Forensic science international Genetics. 2011;5(3):170-80. DOI: https://doi.org/10.1016/j.fsigen.2010.02.004

45. Daniel R, Santos C, Phillips C, Fondevila M, van Oorschot RA, Carracedo A, et al. A SNaPshot of next generation sequencing for forensic SNP analysis. Forensic science international Genetics. 2015;14:50-60. DOI: https://doi. org/10.1016/j.fsigen.2014.08.013

46. Rosenberg NA, Pritchard JK, Weber JL, Cann HM, Kidd KK, Zhivotovsky LA, et al. Genetic structure of human populations. Science. 2002;298(5602):2381-5. DOI: https:// doi.org/10.1126/science.1078311

47. Rajeevan H, Soundararajan U, Pakstis AJ, Kidd KK. Introducing the Forensic Research/Reference on Genetics knowledge base, FROG-kb. Investigative genetics. 2012;3(1):18. DOI: https://doi.org/10.1186/2041-2223-3-18

48. Kidd KK, Soundararajan U, Rajeevan H, Pakstis AJ, Moore KN, Ropero-Miller JD. The redesigned Forensic Research/ Reference on Genetics-knowledge base, FROG-kb. Forensic science international Genetics. 2017;33:33-7. DOI: https://doi.org/10.1016/j.fsigen.2017.11.009

49. Pakstis AJ, Kang L, Liu L, Zhang Z, Jin T, Grigorenko EL, et al. Increasing the reference populations for the 55 AISNP panel: the need and benefits. Int J Legal Med. 2017;131(4):913-7. DOI: https://doi.org/10.1007/s00414016-1524-z

50. Amigo J, Salas A, Phillips C, Carracedo A. SPSmart: adapting population based SNP genotype databases for fast and comprehensive web access. BMC bioinformatics. 2008;9:428. DOI: https://doi.org/10.1186/1471-2105-9-428

51. Kayser M, de Knijff P. Improving human forensics through advances in genetics, genomics and molecular biology. Nature reviews Genetics. 2011;12(3):179-92. DOI: https://doi. org/10.1038/nrg2952

52. Kayser M, Schneider PM. DNA-based prediction of human externally visible characteristics in forensics: motivations, scientific challenges, and ethical considerations. Forensic science international Genetics. 2009;3(3):154-61. DOI: https://doi.org/10.1016/j.fsigen.2009.01.012v 